\title{
PENGARUH SALES PROMOTION GIRL DAN FAKTOR INDIVIDU TERHADAP KEPUTUSAN PEMBELIAN ROKOK LUCKY STRIKE DI KOTA MAKASSAR
}

\section{The Effect Of Sales Promotion Girl and Individual Factors On The Decision Of Purchase Of Lucky Strike Cigarette In Makassar City}

\author{
Adi \\ Email: aditweingberg@gmail.com \\ Prodi Manajemen/STIE Makassar Maju \\ Jl. Perintis kemerdekaan km.12
}

\begin{abstract}
ABSTRAK
Lucky Strike merupakan salah satu produk rokok yang di produksi oleh Bentoel Group yang kini marak dipasarkan di Kota Makassar melalui sales promotion girl. Tujuan dari penelitian ini adalah untuk mengetahui apakah sales promotion girl dan faktor individu berpengaruh terhadap keputusan pembelian rokok Lucky Strike di Kota Makassar. Dalam mencapai tujuan penelitian ini maka metode yang digunakan dalam penelitian adalah pendekatan kuantitatif dengan menggunakan data sekunder dan primer. Populasi dalam penelitian ini adalah seluruh konsumen rokok lucky strike di Kota Makassar dengan jumlah populasi tidak di ketahui. Teknik sampel menggunakan purposive sampling, penentuan jumlah sampel mengunakan pendekatan Roscoe yaitu jumlah anggota sampel minimal 10 kali dari jumlah variabel yang diteliti. Dengan demikian maka jumlah sampel yang digunakan sebanyak 40 orang. Hasil olah data yang di peroleh melalui aplikasi SPSS menunjukkan sales promotion girl dan faktor individu secara parsial dan simultan terhadap keputusan pembelian berpengaruh positif dan signifikan.

Kata Kunci: Sales Promotion Girl; Faktor Individu; Keputusan Pembelian.

ABSTRACT

Lucky Strike is one of the cigarette products produced by the Bentoel Group which is now widely marketed in Makassar City through sales promotion girls. The purpose of this study was to determine whether the sales promotion girl and individual factors influence the buying decision of Lucky Strike cigarettes in Makassar City. In achieving the objectives of this study, the method used in the study is a quantitative approach using secondary and primary data. The population in this study were all lucky strike cigarette consumers in Makassar City with an unknown population. The sample technique used purposive sampling, the determination of the number of samples using the Roscoe approach, namely the number of sample members at least 10 times the number of variables studied. Thus, the number of samples used was 40 people. The results of data processing obtained through the SPSS application show that sales promotion girls and individual factors partially and simultaneously on purchasing decisions have a positive and significant effect.
\end{abstract}

Keywords: Sales Promotion Girl, Individual Factors, Purchase Decisions. 


\section{PENDAHULUAN}

Bentoel Group yang merupakan sala satu perusahaan rokok terbesar di Indonesia yang memproduksi produk rokok Lucky Strike melakukan upaya pengenalan kepada masyarakat kota Makassar khususnya pada kalangan pria dengan menggunakan jasa sales promotion girl (SPG) sebagaimana yang di lakukan oleh produsen rokok lainnya seperti Sampoerna dan Marlboro yang juga menggunakan jasa sales promotion girl dalam mempromosikan produknya untuk memengaruhi seorang konsumen. Keberadaan seoarang sales promotion girl tidak jarang di jumpai di tempat keramaian seperti warung Kopi (warkop), café dan tempat keramaian lainnya yang ramai di kunjungi oleh kalangan pria.

Tampilan yang menarik dan kemampuan komunikasi yang di miliki seorang sales promotion girl (SPG) di harapkan mampu memengaruhi seorang konsumen untuk melakukan pembelian sebagaimana yang dikemukakan oleh (Nitisemito 2001) berpendapat bahwa sebagai salah satu pendukung pemasaran suatu produk maka diperlukan tenaga promosi suatu produk sehingga mampu menarik konsumen. Selanjutnya,dengan kemampuan berpromosi yang dimiliki seorang sales promotion girl akan mampu memberikan berbagai informasi yang berkaitan dengan produk. Teori keterkaitan antara sales promotion girl dan keputusan pembelian telah dibuktikan oleh (Wicaksono 2015) melalu penelitiannya berpendapat bahwa terdapat hubungan yang positif antara sales promotion girl terhadap keputusan pembelian pada konsumen Smartphone Samsung Indonesia.

Keputusan seseorang konsumen untuk membeli suatu produk tidak hanya bergantung pada sejauh mana seorang SPG mampu memengaruhi konsumen tetapi juga dipengaruhi faktor lain seperti karakteristik pribadi sebagaimana yang di ungkapkan oleh (Purimahua dalam Amalia 2011) mengatakan bahwa keputusan pembelian dipengaruhi oleh karakteristik pribadi yang unik dari masing-masing individu, seperti jenis kelamin, usia dan tahapan dalam siklus hidup, kepribadian, konsep diri dan gaya hidup. Keterkaitan antara factor individual terhadap keputusan pembelian telah dibuktikan oleh (Cahyono dan Kusumaningrum 2016) dalam penelitiannya menemukan bahwa factor individual berpengaruh positif dan signifikan terhadap keputusan pembelian Obat. Dari penjelasan di atas peneliti tertarik mengembangkan penelitian dengan menggabungkan variabel sales promotion girl dan faktor individu sebagai varial yang memengaruhi keputusan pembelian. 


\section{METODE PENELITIAN}

Untuk membuktikan kebenaran dari dugaan yang masih bersifat sementara maka pendekatan studi ini berdasarkan jenis data dan analisisnya adalah penelitian kuantutatif dalam menjawab rumusan masalah. (Sugiyono 2015) mengatakan bahwa penelitian kuantitatif adalah penelitian berupa angka-angka dan analisisnya menggunakan statistik. Sumber data dalam penelitian ini adalah data primer dimana data ataupun informasi diperoleh dari sumber pertama atau responden. Sedangkan teknik pengumpulan data yang dilakukan dalam studi adalah studi lapang (field research) dengan cara menyebar kuesioner kepada responden.

Penelitian ini dilakukan di kota Makassar Sulawesi Selatan dengan rentang waktu tiga bulan yang dimulai pada bulan januari sampai maret 2018. Populasi penelitian adalah seluruh konsumen rokok lucky strike di Kota Makassar dengan jumlah populasi tidak di ketahui. Teknik sampel menggunakan purposive sampling, penentuan jumlah sampel mengunakan pendekatan Roscoe yaitu jumlah anggota sampel minimal 10 kali dari jumlah variabel yang diteliti. Dengan demikian maka jumlah sampel yang digunakan sebanyak 40 orang.

Analisis data menggunakan regresi linear berganda dengan persamaan sebagai berikut (Arif 2010):

$$
Y=\beta_{0}+\beta_{1} X_{1}+\beta_{2} X_{2}+\beta_{3} X_{3}+\epsilon
$$

$$
\begin{array}{ll}
\text { Keterangan: } & \\
\mathbf{Y} & =\text { Variabel dependen } \\
\boldsymbol{\beta}_{\mathbf{0}} & =\text { Konstanta (nilai Y apabila } \mathrm{X}=0 \text { ) } \\
\mathbf{X}_{\mathbf{1}}, \ldots \ldots \mathbf{X}_{\mathbf{n}} & =\text { variabel Independen } \\
\boldsymbol{\beta}_{\mathbf{1}} \boldsymbol{\beta}_{\mathbf{2}} \boldsymbol{\beta}_{\mathbf{3}} & =\text { Koefisien regresi } \\
\mathbf{\epsilon} & =\text { Peubah acak (variabel diluar penelitian) }
\end{array}
$$

\section{HASIL DAN PEMBAHASAN}

Berdasarkan hasil pengolahan data yang dilakukan dengan menggunakan SPSS maka hasil uji dan pembahasan dijabarkan sebagai berikut ini: 


\section{Uji normalitas}

Hasil uji normalitas pada penelitian ini dapat dilihat pada gambar 1 berikut ini.

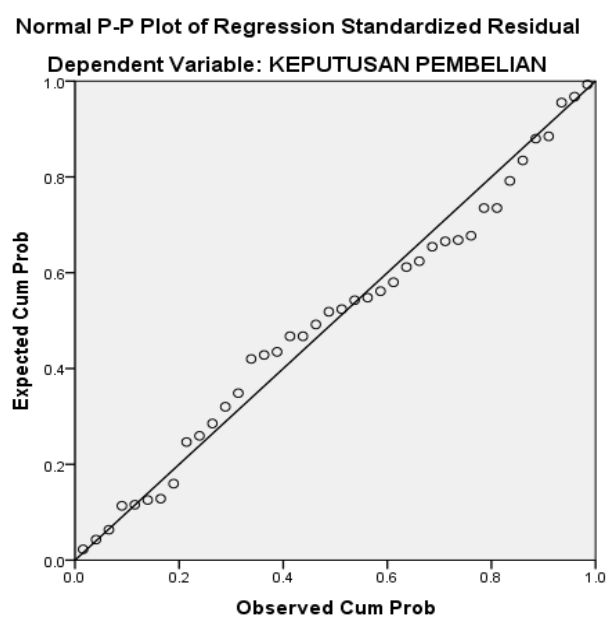

Gambar 1. Uji normalitas

Berdasarkan tampilan grafik Normal P-plot di atas, dapat disimpulkan bahwa pada grafik normal terlihat titik-titik yang penyebarannya mengikuti arah garis diagonal sehingga dapat kita katakan bahwa model regresi tersebut berdistribusi normal.

\section{Uji Heteroskesdastisitas}

Hasil pengujian heteroskedastisitas dapat dilihat pada gambar di bawah ini.

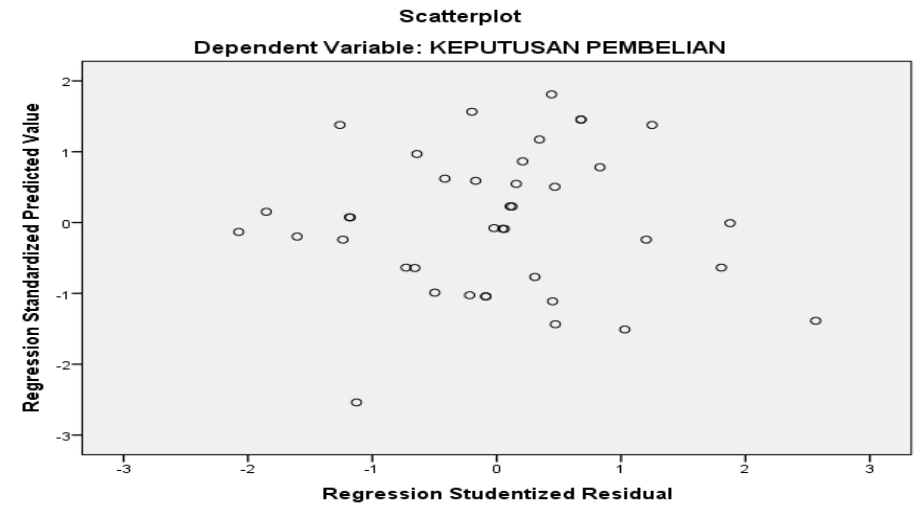

Gambar 2.Uji heteroskedastisitas

Berdasarkan gambar 2 di atas, dapat diketahui bahwa data (titik-titik) menyebar di atas dan di bawah garis nol, tidak berkumpul di satu tempat, serta tidak membentuk pola tertentu sehingga dapat disimpulkan bahwa uji regresi ini tidak terjadi masalah heteroskesdastisitas. 


\section{Analisis Regresi Linier Berganda}

Teknik regresi berganda digunakan untuk menguji pengaruh dua atau lebih variabel independen terhadap satu variabel dependen.Hasil uji regresi linear dapat dilihat pada tabel 1 berikut ini.

Tabel 1 Hasil Uji Regresi Linier Berganda dan uji t

\begin{tabular}{|c|c|c|c|c|c|}
\hline \multicolumn{6}{|c|}{ Coefficients $^{a}$} \\
\hline \multirow[t]{2}{*}{ Model } & \multicolumn{3}{|c|}{ Unstandardized Coefficients Standardized Coefficients } & \multirow[t]{2}{*}{$\mathrm{t}$} & \multirow[t]{2}{*}{ Sig } \\
\hline & B & Std. Error & Beta & & \\
\hline (Constant) & 3,495 & 1,118 & & 3,126 &, 003 \\
\hline $1 S P G$ &, 157 & 045 & ,229 & 3,464 &, 001 \\
\hline FAKTORINDIVIDU & ,629 & ,053 & ,777 & 11,758 &, 000 \\
\hline
\end{tabular}

a. Dependent Variable: KEPUTUSAN PEMBELIAN

Berdasarkan tabel 1 di atasa maka model persamaan regresi pada penelitian ini adalah sebagai berikut.

$$
Y=3.495+0.229 X_{1}+0.777 X_{2}+€
$$

Dari persamaan tersebut menunjukkan bahwa jika variabel independen (sales promotion girl dan faktor individu) diasumsikan tidak mengalami perubahan (konstan) atau sama dengan nol maka nilai Y (Keputusan pembelian) adalah sebesar $3.495 \%$. sementara koefisien variabel sales promotion girl besaran pengaruh terhadap keputusan pembelian akan bertambah sebesar 0.229 jika ditingkatkan sebesar satu satuan. Sedangkan besaran pengaruh faktor individu terhadap keputusan pembelian akan bertambah sebesar 0.777 jika di tingkatkan sebesar satu satuan.

\section{Uji Parsial (t)}

Dengan mensubtitusi parameter estimasi kedalam model penelitian maka diperoleh hasil uji t sebagai berikut :

\section{a. Hipotesis 1: Pengaruh sales promotion girl terhadap keputusan pembelian.}

Nilai thitung untuk variabel sales promotion girl sebesar 3.464 dimana nilai ini lebih besar dari $t_{\text {tabel }} 2.021$ sedangkan nilai signifikansi lebih kecil dari nilai probabilitas alpha 0.05 dengan nilai signifikansi sales promotion girl sebesar 0.001. Dengan kecilnya $t_{\text {tabel }}$ daripada $t_{\text {hitung }}$ maka 
kesimpulan yang dibuat adalah menolak $\mathrm{H}_{0}$ dan menerima $\mathrm{H}_{1}$ sehingga dapat dikatakan bahwa sales promotion girl berpengaruh postif dan signifikan terhadap keputusan pembelian rokok lucky strike di kota Makassar.

\section{b. Hipotesis 2: pengaruh faktor individu terhadap keputusan pembelian.}

Nilai thitung untuk variabel faktor individu sebesar 11.758 dimana nilai ini lebih besar dari t tabel 2.021 sedangkan nilai signifikansi lebih kecil dari nilai probabilitas alpha 0.05 dengan nilai signifikansi faktor individu sebesar 0.000. Dengan kecilnya $t_{\text {tabel }}$ daripada $t_{\text {hitung maka }}$ kesimpulan yang dibuat adalah menolak $\mathrm{H}_{0}$ dan menerima $\mathrm{H}_{1}$ sehingga dapat dikatakan bahwa faktor individu berpengaruh postif dan signifikan terhadap keputusan pembelian rokok lucky strike dikota Makassar.

\section{Uji Simultan (f)}

Hasil uji F pada penelitian ini dapat di lihat pada tabel 2 berikut ini.

\section{Tabel 2 uji simultan (f)}

\begin{tabular}{|c|c|c|c|c|c|c|}
\hline \multicolumn{7}{|c|}{ ANOVA $^{a}$} \\
\hline & lodel & Sum of Squares & $\mathrm{df}$ & Mean Square & $\mathrm{F}$ & Sig. \\
\hline \multirow{3}{*}{1} & Regression & 315,937 & 2 & 157,968 & 330,906 &, $000^{b}$ \\
\hline & Residual & 17,663 & 37 & ,477 & & \\
\hline & Total & 333,600 & 39 & & & \\
\hline
\end{tabular}
a. Dependent Variable: KEPUTUSAN PEMBELIAN
b. Predictors: (Constant), FAKTOR INDIVIDU, SPG

Berdasarkan tabel 4.18 dapat dilihat bahwa hasil uji $\mathrm{F}$ menunjukkan nilai $\mathrm{F}_{\text {hitung }}$ sebesar 330.906 dengan signifikansi sebesar 0.000. Nilai $F_{\text {hitung }}$ di atas lebih besar dari $F_{\text {tabel }}$ dengan nialai sebesar 2.866 serta nilai sig.hitung lebih kecil dari nilai alpha 0.05 sehingga keputasan yang bisa diambil adalah menolak $\mathrm{H}_{0}$ dan menerima $\mathrm{H}_{1}$ yang berarti bahwa sales promotion girl dan faktor individu secara bersama-sama (simultan) berpengaruh positif dan signifikan terhadap keputusan pembelian rokok lucky strike di kota Makassar.

\section{Koefisien determinasi}

Analisis koefisien determinasi $\left(\mathrm{R}^{2}\right)$ atau $\mathrm{R}$-square digunakan untuk melihat kemampuan seberapa besar variabel independen yaitu desain produk, sales promotion girl dan faktor individu 
mampu menjelaskan variabel dependennya yaitu (keputusan pembelian). Adapun nilai $\left(\mathrm{R}^{2}\right)$ atau R-square dapat dilihat pada tabel 3 berikut ini.

Tabel 3 koefisien determinasi

\begin{tabular}{lrrrr}
\multicolumn{5}{c}{ Model Summary } \\
\hline Model & $\mathrm{R}$ & $\mathrm{R}$ Square & $\begin{array}{c}\text { Adjusted R } \\
\text { Square }\end{array}$ & $\begin{array}{c}\text { Std. Error of the } \\
\text { Estimate }\end{array}$ \\
\hline 1 &, $973^{\mathrm{a}}$ &, 947 & &, 944 \\
\hline
\end{tabular}

a. Predictors: (Constant), FAKTOR INDIVIDU, SPG

Dari tabel 3 di atas terlihat nilai koefisien determinasi $\left(\mathrm{R}^{2}\right)$ sebesar 0.947 menunjukkan bahwa sales promotion girl dan faktor individu sebagai variabel independen mampu menjelaskan keputusan pembelian produk rokok lucky strike di kota Makassar sebagai variabel dependen sebesar $94.7 \%$, sedangkan sisanya sebesar 5.3\% dijelaskan oleh faktor-faktor lain yang tidak dimasukkan dalam penelitian ini misalnya iklan, harga dan lain-lain yang dianggap mampu memengaruhi keputusan pembelian rokok Lucky Strike di kota Makassar.

\section{KESIMPULAN DAN SARAN}

Berdasarkan hasil analisis data dan pengujian hipotesis yang telah diuraikan sebelumnya maka penulis mengambil kesimpulan bahwa Secara parsial dan simultan variabel sales promotion girl, dan faktor individu berpengaruh positif dan signifikan terhadap keputusan pembelian. Dalam artian bahwa jika sales promotion girl, dan faktor individu diimplementasikan dengan baik maka keputusan pembelian akan meningkat. Karena itu implementasi strategi promosi melalui sales promotion girl dan faktor individu menjadi penting untuk diperhatikan dalam menentukan keputusan pembelian.

Adapun saran yang peneliti ingin sampaikan kepada pihak terkait agar Strategi pemasaran melalui sales promotion girl sebaiknya dipertahankan dan ditingkatkan serta memerhatikan kepribadian konsumen dalam menawarkan produk agar aktivitas tetap produktif.

\section{DAFTAR PUSTAKA}

Abbas firdayanti.2015. Pengaruh. Marketing Mix Terhadap Kepuasan Konsumen (PadaHome Industry Moshimoshi Cake Samarinda). eJournal Administrasi Bisnis, 2015, 3 (1): 244258. ISSN 2355-5408. 
Andini, P. 2012. Analisis Faktor-Faktor yang Mempengaruhi Keputusan Pembelian Mobil Hyundai i20 (Studi Kasus pada Konsumen Mobil Hyundai i20 diSemarang). skripsi. universitas diponegoro semarang.

Angipora, Marius P, 2002. Dasar-dasar Pemasaran, Edisi Kedua, Cetakan. Kedua, PT. Raja Grafindo Persada, Jakarta.

Anoki Herdian Dito.2010.Pengaruh Kompensasi Terhadap Kinerja Karyawan PT. Slamet Langgeng Purbalingga Dengan Motivasi Sebagai Variabel Intervening. Tesis. Magister Manajemen. Undip Semarang.

Ayu Paramita Antari dan David Hizkia Tobing, 2014. Hubungan Antara Citra Raga dengan Persepsi Terhadap Produktivitas Sales Promotion Girls Kosmetik Kecantikan di Kota Denpasar.JurnalPsikologiUdayana. ISSN: 2354-56071(2), 335-343.

Bagus, R. W. 2015. Pengaruh Sales Promotion Girl Smartphone Samsung Terhadap Keputusan Pembelian ( Studi Pada Konsumen Smartphone Samsung Indonesia Tahun 2015 ), 2(3), 2884-2890.

Dian Puspita Rini. 2013. Pengaruh Faktor Kebudayaan, Sosial, Pribadi, Dan Psikologi Terhadap Proses Keputusan Pembelian Produk Pizza (Studi Pada Pizza Hut Cabang Jalan Jenderal Sudirman No. 53 Yogyakarta). Skripsi. UniversitasNegeri Yogyakarta

Dwi Cahyono dan Kusumaningrum. 2016. Pengaruh Faktor-Faktor Individual Dan Bauran Pemasaran Terhadap Keputusan Pembelian Obat Lewat Resep Pada Apotik Rawat Jalan Di Instalasi Farmasi Rumah Sakit Jember Klinik. Jurnal Sains Manajemen \& Bisnis Indonesia Volume VI, No. 2.

Edwar, M. (n.d.). 2017. Pengaruh Sales Promotion Girl Dan Sales Promotion Boy Terhadap KeputusanPembelian Smartphone Oppo Di Area Gresik Kota. Jurnal Pendidikan Tata Niaga ( JPTN ).Volume 01 Nomor 02. ISSN: 2337-6708.

Firada Amalia. 2011. Analisis Pengaruh Faktor Budaya, Sosial, Pribadi Dan Psikologis Terhadap Keputusan Pembelian Minuman PenambahTenaga Cair Merek M-150 Di Semarang. Skrpsi. Universitas Diponegoro Semarang

Gujarati, Damor. 1995. Ekometrika Dasar. Alih bahasa sumarno zain. Erlangga: Jakarta.

https://komunitaskretek.or.id. Empat merek rokok paling laris diindonesi. Diakses 2018.

Ismail, H. 2017. Pengaruh Diferensiasi Produk Dan Promosi Terhadap Keputusan Pembelian Produk Smartphone OPPO F1s ( Studi Kasus Pada Toko Radja Ponsel Di Samarinda ), 5(3), 675-689.

KadirAbd. Rahman. 2012. Manajemen Pemasaran Jasa: Pendekatan Integratif antara Teori dan Implementasi. PT IPB Press. Taman Kencana Bogor.

Kotler dan Keller. 2013. Manajemen Pemasaran Jilid 2 Edisi 13. Jakarta : Penerbit Erlangga. 
Kotler dan keller. 2007. Manajemen pemasaran. Jakarta. Pt. Indeks.

Muanas, A., \& Suhermin. 2014. Pengaruh Produk, Harga dan Promosi terhadap Keputusan Pembelian Mobil Buana Indomobil Trada. Jurnal Ilmu \& Riset Manajemen, 3(12), 1-17.

M. Mursid. 2010. Manajemen Pemasaran, PT Bumi Aksara. Jakarta.

Mustofa Muh Fuaidi. 2016. Pengaruh Desain Produk dan Harga Terhadap Pembelian Suzuki Satria Fu 150 cc (Studi Pada Pengguna Sepeda Motor Suzuki Satria Fu 150 cc Di Surabaya). Jurnal Ilmu Manajemen Volume 4 Nomor 4

Sugiyono. 2015. Metode Penelitian Kuantitatif, Kualitatif dan R\&D. Cetakan ke-22. Bandung Alfabeta

Supriyono, \& Iskandar, D. 2015. Pengaruh faktor budaya, sosial, individu dan psikologis terhadap keputusan konsumen membeli di indomaret. Jurnal Kelola, 2(3), 43-60.

Syukron Ma'mun. 2015.Sensual Marketing (Memasarkan Produk Dengan Menggunakan Jasa Sales Promotion Girls) Menurut Perspektif Ekonomi Islam Studi Kasus Pada PT. Smartfren Telecom Cabang Semarang. Skripsi. Universitas Islam Negeri Walisongo Semarang.

SWA, 2010. Edisi I/2010, Jakarta

Tiro Muhammad Arif.2010. Analisis Korelasi dan Regresi. edisi ke-3. Makassar. Andira Publisher.

www.bentoelgroup.com

Widyasari, S., \& Fifilia, E. T. 2009. Analisis Pengaruh Produk, Harga, Promosi Dan Lokasi Terhadap Keputusan Pembelian Rumah ( Studi pada Perumahan Graha Estetika Semarang ). Telaah Manajemen, 6(2), 159-169. 